\title{
Does autoimmunity to $S$-antigen play a role in Fuchs' heterochromic cyclitis?
}

\author{
E La Hey, L Broersma, R van der Gaag, G S Baarsma, A Rothova, A Kijlstra
}

\begin{abstract}
Autoimmunity directed against retinal or choroidal antigens has been suggested to play a role in the chorioretinal lesions observed in patients with Fuchs' heterochromic cyclitis. This hypothesis was addressed and patients with Fuchs' heterochromic cyclitis were tested for cellular immunity (migration inhibitory factor assay) against human retinal S-antigen. A significantly higher percentage of patients with Fuchs' heterochromic cyclitis had a positive cellular autoimmune response to $S$-antigen than healthy controls and other patients with anterior uveitis. This finding is remarkable since Fuchs' heterochromic cyclitis is generally classified as an anterior uveitis and patients with Fuchs' heterochromic cyclitis without chorioretinal lesions also had a positive test. In view of these results and a sensitisation against a corneal antigen reported earlier in Fuchs' heterochromic cyclitis, it is suggested that a chronic low grade grade anterior uveitis or chorioretinitis of unknown origin may cause the release of potent autoantigens in these patients.
\end{abstract}

(BrF Ophthalmol 1993; 77: 436-439)

Many studies have been published to elucidate the aetiology of Fuchs' heterochromic cyclitis but it remains unknown. Although it is considered as a separate nosological entity, associations between Fuchs' heterochromic cyclitis and other diseases have frequently been described.$^{1-13}$ Most of these studies reported on the assumed association between Fuchs' heterochromic cyclitis and ocular toxoplasmosis. ${ }^{1-7}$ In $7 \cdot 5 \%$ to $60 \%$ of the patients with Fuchs' heterochromic cyclitis the presence of chorioretinal scars which were clinically consistent with ocular toxoplasmosis was reported. In a recent study we found

Table 1 Clinical data of patients and controls

\begin{tabular}{|c|c|c|c|c|c|c|c|c|}
\hline \multirow[b]{2}{*}{ Group } & \multirow[b]{2}{*}{ Diagnosis } & \multirow[b]{2}{*}{ Number } & \multirow{2}{*}{$\begin{array}{l}\text { Malel } \\
\text { female }\end{array}$} & \multicolumn{2}{|c|}{ Age (years) } & \multirow{2}{*}{$\begin{array}{l}\text { Disease } \\
\text { activity } \\
\text { Activel } \\
\text { low-grade }\end{array}$} & \multicolumn{2}{|l|}{ Therapy } \\
\hline & & & & Mean & Range & & Topical $^{\star}$ & Systemict \\
\hline $\begin{array}{l}\text { A } \\
\text { B } \\
\text { C } \\
\text { D } \\
\mathbf{E}\end{array}$ & $\begin{array}{l}\text { Fuchs' heterochromic cyclitis } \\
\text { Active Toxoplasma uveitis } \\
\text { Anterior uveitis } \\
\text { Pan and posterior uveitis } \\
\text { Healthy controls }\end{array}$ & $\begin{array}{l}13 \\
39 \\
19 \\
31 \\
26\end{array}$ & $\begin{array}{c}6 / 7 \\
19 / 20 \\
9 / 10 \\
15 / 16 \\
14 / 12\end{array}$ & $\begin{array}{l}39 \\
31 \\
49 \\
37 \\
37\end{array}$ & $\begin{array}{l}22-71 \\
12-77 \\
23-77 \\
11-72 \\
28-63\end{array}$ & $\begin{array}{l}0 / 13 \\
39 / 0 \\
19 / 0 \\
31 / 0 \\
-\end{array}$ & $\begin{array}{l}3 \\
- \\
10 \\
11 \\
-\end{array}$ & $\begin{array}{l}- \\
\overline{-} \\
\overline{5}\end{array}$ \\
\hline
\end{tabular}

$\star$ Steroid eye drops.

†Prednisone ( $20-40 \mathrm{mg} /$ day) or prednisone (5-10 mg/day) and cyclosporin A (5-10 mg/kg/day). toxoplasmosis-like chorioretinal lesions in nine $(10 \cdot 2 \%)$ out of 88 patients with Fuchs' heterochromic cyclitis. ${ }^{7}$ No association between Fuchs' heterochromic cyclitis and ocular toxoplasmosis could be proved by extensive laboratory tests for toxoplasmosis. Furthermore, non-specific chorioretinal scars were present in patients with Fuchs' heterochromic cyclitis along with negative laboratory results for Toxoplasma gondii. Arffa and Schlaegel ${ }^{3}$ also observed non-specific scars in patients with Fuchs' heterochromic cyclitis. Moreover, these authors described two patients who had fundus lesions characteristic of toxoplasmosis, but negative titres for Toxoplasma in undiluted serum. They suggested that these scars were of non-Toxoplasma origin and could result from autoimmunity against retinal or choroidal antigens. ${ }^{3}$ We have addressed this hypothesis and looked for a possible role of retinal S-antigen in the pathogenesis of Fuchs' heterochromic cyclitis by means of a test for cellular immunity (migration inhibitory factor (MIF) assay) to human S-antigen.

\section{Patients and methods}

PATIENT AND CONTROL POPULATION

Fresh blood was obtained from 13 patients with Fuchs' heterochromic cyclitis (group A) seen at the university eye clinics in Amsterdam or Rotterdam. The diagnosis was based on the presence of all of the following criteria, established from data in the literature ${ }^{1421}$ : (1) the absence of acute symptoms like severe redness, pain, or photophobia; (2) the presence of characteristic small white stellate keratic precipitates; (3) minimal cells and flare in the anterior chamber; (4) diffuse iris stromal atrophy, with or without patchy loss of the iris pigment epithelium; (5) the absence of synechiae; (6) the

\author{
Department of \\ Ophthalmology, \\ University of Amsterdam \\ A Rothova \\ The Eye Hospital, \\ Rotterdam, The \\ Netherlands \\ G S Baarsma \\ Correspondence to: \\ Dr E La Hey, The \\ Netherlands Ophthalmic \\ Research Institute, PO Box \\ 12141,1100 AC, Amsterdam, \\ The Netherlands. \\ Accepted for publication \\ 10 February 1993 \\ Department of
Ophthalmo-Imm \\ Ophthalmic Research \\ Institute, Amsterdam \\ L Broersma \\ $R$ van der Gaag
}


Table 2 Uveitis entities included in groups $C$ and $D$ and their results of immune testing

\begin{tabular}{|c|c|c|c|}
\hline Group & Uveitis entity & Number & $\begin{array}{l}\text { Positive } \\
\text { response to } \\
\text { S-antigen }\end{array}$ \\
\hline C & $\begin{array}{l}\text { Anterior uveitis } \\
\text { Undetermined } \\
\text { HLA-B27 associated } \\
\text { Sarcoidosis } \\
\text { Syphilis } \\
\text { Herpes zoster uveitis }\end{array}$ & $\begin{array}{c}19 \\
12 \\
4^{\star} \\
1 \\
1 \\
1\end{array}$ & $\begin{array}{r}2 \\
1 \\
1 \\
- \\
-\end{array}$ \\
\hline \multirow[t]{6}{*}{ D } & $\begin{array}{l}\text { Pan and posterior uveitis } \\
\text { Undetermined } \\
\text { Sarcoidosis } \\
\text { Pars planitis } \\
\text { Idiopathic retinal }\end{array}$ & $\begin{array}{r}31 \\
12 \\
4 \\
3\end{array}$ & $\begin{array}{c}12 \\
5 \dagger \\
1 \\
1\end{array}$ \\
\hline & $\begin{array}{l}\text { vasculitis } \\
\text { Behçet's disease } \\
\text { Birdshot }\end{array}$ & $\begin{array}{l}2 \\
2\end{array}$ & $\begin{array}{l}1 \\
1\end{array}$ \\
\hline & $\begin{array}{l}\text { retinochoroidopathy } \\
\text { Vogt-Koyanagi-Harada's }\end{array}$ & 1 & 1 \\
\hline & $\begin{array}{l}\text { disease } \\
\text { Acute retinal necrosis } \\
\text { Acute multifocal placoid }\end{array}$ & $\begin{array}{l}2 \\
2\end{array}$ & - \\
\hline & $\begin{array}{l}\text { pigment epitheliopathy } \\
\text { Presumed ocular }\end{array}$ & 1 & - \\
\hline & $\begin{array}{l}\text { histoplasmosis } \\
\text { Lyme borreliosis }\end{array}$ & $\begin{array}{l}1 \\
1\end{array}$ & 1 \\
\hline
\end{tabular}

*One patient also had ankylosing spondylitis.

tOne patient with diabetes mellitus developed retinal detachment and severe panuveitis after cataract extraction with intraocular lens implantation.

presence of cells and opacities in the anterior vitreous. Heterochromia, cataract, and glaucoma could be present, but were not essential criteria for the diagnosis.

Results were compared with other types of uveitis (groups B, C, and D) and healthy controls (groups E). Blood samples were obtained from patients with active uveitis: some of them presented for the first time and blood samples were obtained as part of their examination for uveitis. Details on mean age, age range, male to female ratio, clinical activity of the disease, and therapy at the time of testing of all groups are presented in Table 1.

Group B consisted of 39 patients with active ocular toxoplasmosis. This diagnosis was based on an active unilateral focal necrotising retinochoroiditis, often in satellite formation, with associated vitreous inflammation and the appearance of typical scars with hyperpigmentation after clearing of the vitreous. ${ }^{22}$ Group $C$ consisted of 19 consecutive patients with anterior uveitis of various aetiologies. Group D comprised 31 consecutive patients with pan or posterior uveitis of various aetiologies (including pars planitis $n=3$ ), that were not of Toxoplasma origin (Table 2). At the same time 26 similar blood samples were obtained from sex and age-matched healthy laboratory staff without a history of ocular pathology to serve as controls (Group E).

For all groups blood samples were collected from consecutive patients during a specific (limited) time period and no selection was made. To establish the correct diagnosis a retrospective review of clinical records of these uveitis patients, seen at the university eye clinics of Amsterdam and Rotterdam, was performed.

HUMAN S-ANTIGEN

Human S-antigen was isolated from retinas of human cadaver eyes from which the corneas had been removed for transplantation. These retinas were stored at $-20^{\circ} \mathrm{C}$ until use. The isolation of human S-antigen was performed as described by Doekes et al..$^{23}$ A $50 \%$ ammonium sulphate precipitation of retinal extract was followed by DEAE (DE-52, Whatman Corporation, Kent) anion exchange chromatography and gel filtration. ${ }^{23}$

MIGRATION INHIBITORY FACTOR (MIF) ASSAY Cellular immune reactivity against human S-antigen was tested in a two step migration inhibition assay, as described in detail earlier. ${ }^{23}$ In the first step of this assay mononuclear cells were incubated with the test antigen. Subsequently the cell free supernatant was tested in a second step for the presence of MIF activity using the human monocytoid U937 cell line as indicator cells.

For the first step, mononuclear cells were isolated from heparinised blood obtained from the patients using density gradient centrifugation on Ficoll-Paque (Pharmacia, Uppsala, Sweden). Cells from one or more controls were always tested on the same day as the patient cells. The cells were washed twice and adjusted to $2.5 \times 10^{6}$ cells per ml culture medium (RPMI 1640 supplemented with $25 \mathrm{mM}$ HEPES, $100 \mathrm{U} / \mathrm{ml}$ penicillin, $0.1 \mathrm{mg} / \mathrm{ml}$ streptomycin (Gibco Ltd, Paisley, Scotland) and $10 \%$ heat inactivated pooled human serum from non-transfused healthy male donors (Central Laboratory of the Blood Transfusion Service, Amsterdam, The Netherlands). One $\mathrm{ml}$ aliquots were dispensed into $10 \mathrm{ml}$ culture tubes. One tube served as medium control for spontaneous MIF production, concanavalin-A (Con-A, $25 \mu \mathrm{g} / \mathrm{ml}$ ) was added to a second tube to test the general mitogenic responsiveness of the cells, and purified human S-antigen $(5 \mu \mathrm{g} / \mathrm{ml})$ was added to a third tube. The tubes were incubated for 20 hours in a humidified incubator at $37^{\circ} \mathrm{C}$ and $5 \%$ $\mathrm{CO}_{2}$. Cell free supernatants were harvested by centrifugation (10 minutes, $1200 \mathrm{~g}$ ) and assayed directly for the presence of MIF or stored at $-20^{\circ} \mathrm{C}$ until use.

For the second step of the assay, a human monocytoid cell (U937) line was used. U937 cells were harvested from permanent in vitro cultures, washed and adjusted to $5 \times 10^{8}$ cells per $\mathrm{ml}$ in culture medium. Seaplaque agarose (FMC Corporation, Rockland, ME, USA) was dissolved in phosphate buffered saline $(20 \mathrm{mg} / \mathrm{ml})$ at $100^{\circ} \mathrm{C}$ for 20 minutes and subsequently diluted $1: 10$ with warm $\left(37^{\circ} \mathrm{C}\right)$ culture medium. Equal volumes of the agarose solution were mixed with the U937 cell suspension and kept at $37^{\circ} \mathrm{C}$. One $\mu l$ droplets were pipetted with a $50 \mu \mathrm{l}$ Hamilton syringe into the centre of wells of a flat bottom 96 well microtitre tray (Nunc, Roskilde, Denmark). The droplets were allowed to set for $\mathbf{3 0}$ minutes at $4^{\circ} \mathrm{C}$ and subsequently $100 \mu \mathrm{l}$ of cell free supernatant, obtained in the first step, was added to each well. Each supernatant was tested in fivefold. The trays were incubated for 20 hours in a humidified incubator at $37^{\circ} \mathrm{C}$ and $5 \% \mathrm{CO}_{2}$ to allow migration of the U937 cells out of the agarose droplets. The areas of monocyte migration were measured and the migration indices (MI) were calculated as follows: 


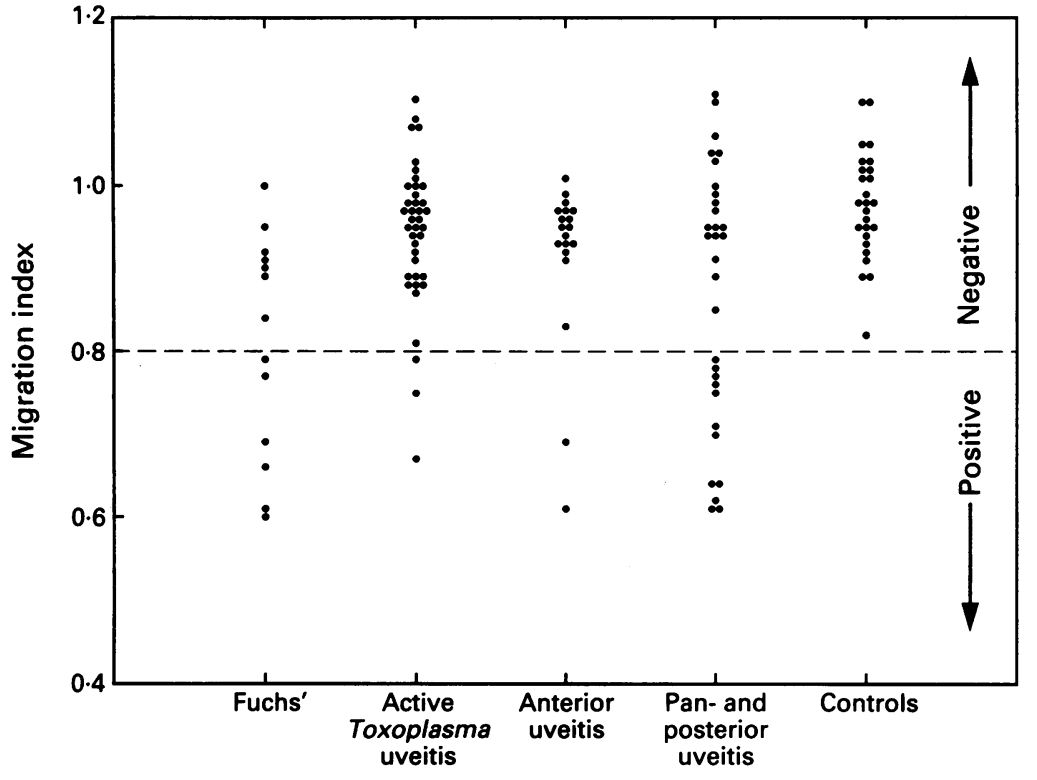

Disease classification

Figure 1 Cellular immune reactivity against human $S$-antigen determined by the migration inhibitory factor (MIF) assay.

\section{Discussion}

Fuchs' heterochromic cyclitis is generally classified as a chronic low grade anterior uveitis. The high percentage of patients with Fuchs' heterochromic cyclitis having a positive cellular autoimmune response to retinal S-antigen, compared with other anterior uveitis patients and healthy controls, is therefore remarkable. It supports the hypothesis of Arffa and Schlaegel ${ }^{3}$ that autoimmune reactions against retinal (S-)antigen(s) may play a role in the pathogenesis of Fuchs' heterochromic cyclitis. Of the 13 patients we tested, two had retinal scars: one with a toxoplasmosis-like scar had a negative response and one patient with a non-specific retinal scar had a positive cellular immune response to S-antigen. These numbers were too small to conclude that there was a possible association between retinal autoimmunity and chorioretinal scars in Fuchs' heterochromic cyclitis.

Nussenblatt $e t a l^{5}$ reported a higher incidence $(40 \%)$ of cellular immune reactivity against $\mathrm{S}$-antigen in patients with ocular toxoplasmosis than in our series. Such a discrepancy may be due to the fact that they used a different cellular immune assay; the lymphocyte transformation test (LTT). We used the MIF assay because it correlates better with type IV allergic reactions (that is, delayed type hypersensitivity (DTH) response) than the LTT and may thus be more appropriate to study presumed autoimmune reactivity. ${ }^{26}$

As reported earlier, ${ }^{232728}$ a significantly higher percentage of the patients with (pan and) posterior uveitis had a positive cellular immune response to S-antigen compared with healthy controls. These results, however, are in disagreement with more recent studies in which no significant differences were found, and normal individuals also had circulating antibodies ${ }^{23} 3032$ and $T$ cells ${ }^{20-31}$ sensitised to retinal (S)-antigen(s). Some discrepancy may be attributed to a different procedure used to purify and obtain the S-antigen: different epitopes may have been present in the various antigen preparations. Moreover, high doses of S-antigen and extended incubation time have been shown to induce in vitro proliferative responses to $S$-antigen in $T$ lymphocytes of uveitis patients, but also in a large proportion of healthy donors. ${ }^{31}$ Results of immune response testing may also vary according to the duration and activity of the disease. ${ }^{29}$ Patients (groups B, C, and D) in the current study all had active disease at the time of testing, except for the patients with Fuchs' heterochromic cyclitis (group A) who had a low grade chronic uveitis. Whether the results may be affected by treatment is insufficiently known. Cyclosporin A (at doses 3-12 mg/kg/day) had little or no effect on the lymphocyte responses to antigens such as keyhole limpet haemocyanin (KLH) or tetanus toxoid..$^{33}$ Treatment with high doses of steroids (100 and $400 \mathrm{mg}$ ) was reported partially to inhibit lymphocyte responses to various mitogens and antigens. ${ }^{34}$ Except for the Toxoplasma uveitis patients, who received no therapy at the time of testing, most of the other uveitis patients in our study received either no therapy or were treated with topical steroids. Only five patients had systemic treatment: two corneal antigen, as described by van der Gaag et al. ${ }^{24}$ Seven of the 13 patients had a positive cellular immune response to this (bovine) $54 \mathrm{kD}$ antigen: three of these seven patients also showed a sensitisation to $S$-antigen. 
received systemic steroids $(20-40 \mathrm{mg} /$ day $)$ and three were treated with prednisone $(5-10 \mathrm{mg} /$ day) and cyclosporin A (5-10 mg/kg/day): three of these five patients had a positive response to S-antigen. We therefore assume that treatment only had a limited effect on the lymphocyte responses of the uveitis patients in this study.

Recently the presence of messenger RNA (mRNA) of S-antigen was demonstrated in irides obtained from uveitis patients and not in control irides. ${ }^{35}$ These findings indicate a possible role for $\mathrm{S}$-antigen in anterior segment inflammation and could account for the fact that some patients with Fuchs' heterochromic cyclitis without chorioretinal scars had a positive cellular immune response to $S$-antigen. This does not explain the low percentage of patients with anterior uveitis who had a positive autoimmune response to S-antigen. Fuchs' heterochromic cyclitis, however, is a chronic anterior uveitis and one can imagine that there is a (more) continuous release of S-antigen than in other forms of anterior uveitis.

Earlier, it was reported that almost $70 \%$ of all patients with Fuchs' heterochromic cyclitis had a cellular immune response against a major corneal antigen $(54 \mathrm{kD}){ }^{24}$ Recently, an increased level of soluble interleukin-2, a marker of (T) lymphocytic activation, was measured in the peripheral blood of patients with Fuchs' heterochromic cyclitis. ${ }^{36}$ As in the current study, these peripheral blood findings point to a systemic lymphocytic activation, which is remarkable since it is generally believed that no systemic involvement occurs in Fuchs' heterochromic cyclitis. One could hypothesise that a primary low grade chronic anterior uveitis causes the leakage of the $54 \mathrm{kD}$ antigen in Fuchs' heterochromic cyclitis, resulting in the presence of specifically sensitised lymphocytes. Similar to the leakage of corneal antigen, a chronic low grade iritis or chorioretinitis of unknown origin may also cause the release of S-antigen, resulting in the observed sensitisation. S-antigen is probably one of several antigens to which sensitisation occurs, and it is therefore likely that the observed autoimmune responses in patients with Fuchs' heterochromic cyclitis may be regarded as epiphenomena.

1 De Abreu ML, Belfort R, Hirata PS. Fuchs' heterochromic cyclitis and ocular toxoplasmosis. Am $\mathcal{F}$ Ophthalmol 1982; 93 : cyclitis and

2 Saraux H, Laroche L, Le Hoang P. Secondary Fuchs's heterochromic cyclitis: a new approach to an old disease. heterochromic cyclitis: a new app

3 Arffa RC, Schlaegel TF. Chorioretinal scars in Fuchs' heterochromic iridocyclitis. Arch Ophthalmol 1984; 102: 1153-5.

4 Pezzi PP, Niutta A, Abdulaziz M, Paroli MP. Fuchs' heterochromic iridocyclitis and toxoplasmic retinochoroiditis. In f Ophthalmol 1987; 1/2: 97-101.

5 Schwab JR. The epidemiologic association of Fuchs' heterochromic iridocyclitis and ocular toxoplasmosis. $A m \mathcal{F}$ Ophthalmol 1991; 111: 356-62.

$6 \mathrm{La}$ Hey E, Rothova A. Fuchs' heterochromic cyclitis in congenital ocular toxoplasmosis. Brf Ophthalmol 1991; 75: 372-3. 7 La Hey E, Rothova A, Baarsma GS, de Vries J, van Knapen F, ated with ocular toxoplasmosis. Arch Ophthalmol 1992; 110: 806-11.

8 Vourre I, Saari M, Tilikainen I, Rasanen O. Fuchs' heterochromic cyclitis associated with retinitis pigmentosa: a chromic cyclitis associated with retinitis pig

9 Francois J, Mastilovic B. L'heterochromie de Fuchs associee aux heredo-degenerescences chorioretiennes. Ann Oculist 1961; 94: 385-96.

10 Winkler A. Retinitis pigmentosa sine pigmento auf dem einen und retinitis pigmentosa mit heterochromie-iridocyclitis auf dem anderen auge. Klin Monatsbl Augenheilkd 1940; 105: $594-600$.

11 Vadot E. Cyclite heterochromique de Fuchs post-traumatique. Bull Soc Ophtalmol Fr 1981; 81: 665-7.

12 Donoso LA, Eiferman RA, Magargal LE. Fuchs' heterochromic cyclitis associated with subclavian steal syndrome. Ann Ophthalmol 1981; 13: 1153-5.

13 Sugar HS, Banks TL. Fuchs' heterochromic cyclitis associated with facial hemiatrophy (sklerodermie en coup de sabre). Am f Ophthalmol 1964; 57: 627-32.

14 Fuchs E Ueber komplikationen der heterochromie. Z Augenheilkd 1906; 15: 191-212.

15 O'Connor R. Doyne lecture: heterochromic iridocyclitis. Trans Ophthalmol Soc UK 1985; 104: 219-31.

16 Liesegang TJ. Clinical features and prognosis in Fuchs' uveitis syndrome. Arch Ophthalmol 1982; 100: 1622-66.

17 Kimura SJ, Hogan MJ, Thygeson P. Fuchs' syndrome of heterochromic cyclitis. Arch Ophthalmol 1955; 54: 179-86.

18 Franceschetti A. Heterochromic cyclitis (Fuchs' syndrome) Am $\mathcal{F}$ Ophthalmol 1955; 39: 50-8.

19 Dernouchamps JP. Fuchs' heterochromic cyclitis: an IUSG study about 550 cases. In: Saari KM, ed. Uveitis update. study about 550 cases. In: Saari KM:

20 Tabbut BR, Howard HT, Williams D. Fuchs' heterochromic iridocyclitis in blacks. Arch Ophthalmol 1988; 106: 1688-90.

21 Loewenfeld IE, Thompson HS. Fuchs's heterochromic cyclitis: a critical review of the literature. I Clinical characteristics of the syndrome. Surv Ophthalmol 1973; 17: 396 457

22 Schlaegel TF Jr. Ocular toxoplasmosis and pars planitis. New York: Grune and Stratton, 1978: 138-72.

23 Doekes G, van der Gaag R, Rothova A, van Kooyk Y, Broersma L, Zaal MJM, et al. Humoral and cellular immun responses to human S-antigen in uveitis. Curr Eye Res 1987 6: $909-19$.

24 van der Gaag R, Broersma L, Rothova A. Immunity to a corneal antigen in Fuchs' heterochromic cyclitis. Invest Ophthalmol Vis Sci 1989; 30: 443-8.

25 Nussenblatt RB, Mittal KK, Fuhrman S, Sharma SD, Palestine AG. Lymphocyte proliferative responses of Palestine AG. Lymphocyte proliferative responses of antigens. Am f Ophthalmol 1989; 107: 632-41.

26 van de Plassche-Boers EM, Drexhage HA, Kokje-Kleingeld $M$, Leezenberg HA. Parameters of T-cell mediated immunity to commensal micro-organisms in patients with chronic purulent rhinosinusitis. A comparison between delayed type hypersensitivity (DTH) skin test, lymphocyte transformation test (LTT) and macrophage migration in hibition (MIF) assay. Clin Exp Immunol 1986; 66: 516-24

27 Nussenblatt RB, Gery I, Ballantine EJ, Wacker WB. Cellular immune responsiveness of uveitis patients to retinal S-antigen. Am F Ophthalmol 1980; 89: 173-9.

28 Wyler DJ, Blackman HJ, Lunde MN. Cellular hypersensitivity to toxoplasmal and retinal antigens in patients with sitivity to toxoplasmal and retinal antigens in patients with toxoplas.

29 de Smet MD, Yamamoto JH, Motchizuki M, Gery I, Singh VK, Shinohara $T$, et al. Cellular immune responses of patients with uveitis to retinal antigens and their fragments. Am $\mathcal{F}$ Ophthalmol 1990; 110: 135-42.

30 Froebel KS, Armstrong SS, Cliffe AM, Urbaniak SJ, Forrester JV. An investigation of the general immune status and specific immune responsiveness to retinal-(S)-antigen in patients with chronic posterior uveitis. Eye 1989; 3: 263-70.

31 Hirose S, Tanaka T, Nussenblatt RB, Palestine AG, Wigger B. Redmond TM, et al. Lymphocyte responses to retinalspecific antigens in uveitis patients and healthy subjects. Cur Eye Res 1988; 7: 393-402.

32 Forrester JV, Stott D, Hercus K. S-antigen in uveitis patients and normal healthy controls. Br $\mathcal{F}$ Ophthalmol 1989; 73: and no. 155 .

33 Palestine AG, Roberge FG, Charous BL, Lane HC, Fauci AS, Nussenblatt RB. The effect of cyclosporin on immunization with tetanus and keyhole limpet hemocyanin (KLH) in humans. F Clin Immunol 1985; 5: 115-21.

34 Fauci AS, Dale DC. The effect of in vivo hydrocortisone on subpopulations of human lymphocytes. $\mathcal{f}$ Clin Invest 1974 ; 53: $240-6$.

35 Chan CC, Li O, Kiuchi T, Shinohara T, Nussenblatt RB Detection of the mRNA of S-antigen from irises of uveitic patients. Invest Ophthalmol Vis Sci 1991; 32: 916

36 Arocker-Mettinger E, Asenbauer T, Ulbrich S, Grabner G. Serum interleukin-2 receptor levels in uveitis. Curr Eye Res 1990; 9 (suppl): 25-9. 